\title{
Cardiac resynchronization therapy- defibrillator pocket infection caused by Mycobacterium fortuitum: a case report and review of the literature
}

\author{
Jun Zhu', Qingluan Yang ${ }^{2}$, Junjie Pan ${ }^{1}$, Haiming Shi ${ }^{1}$, Bo Jin ${ }^{1^{*}}$ and Qiying Chen ${ }^{1 *}$ (D)
}

\begin{abstract}
Background: With the rising utilization of cardiovascular implantable electronic devices (CIEDs), infections secondary to device implantation are increasingly encountered. Staphylococcus aureus and coagulase-negative staphylococci are usually the predominant causative organisms. A CIED infection due to non-tuberculous mycobacteria (NTM) is extremely rare.

Case presentation: A 68-year-old man was admitted to our hospital with a history of pain and swelling at his cardiac resynchronization therapy-defibrillator (CRT-D) pocket site, for 4 days. The CRT-D had been implanted 2 weeks prior. The exudate smear was positive for acid-fast bacilli and culture results revealed rapidly growing nontuberculous mycobacteria (RGM). After an urgent removal of the device followed by 1 year of antibiotic treatment, the patient was completely cured. A new device was finally implanted, 3 years later.

Conclusions: Infections caused by nontuberculous mycobacteria following the implantation of cardiac devices are very rare. The typical manifestations of post-implantation CIED infections caused by RGMs include an early onset, with local redness, swelling, and spontaneous drainage. Systemic symptoms such as fever, chills, and fatigue are absent. Mycobacterium fortuitum is the most common species of RGM implicated in CIED infections, the manifestations of which usually appear within several weeks of the implantation procedure. An urgent removal of the device and appropriate antibiotic therapy are essential therapeutic measures. This is the first such reported case, in which the patient has been re-implanted with another device at the same site, after achieving a complete cure. We followed-up the patient for an additional 3 years and observed that the patient remained free of infection. Our case report shows that though an RGM infection is rare and difficult to treat, it can be completely cured. In addition, we demonstrated that it is subsequently possible to safely re-implant a CIED for the patient, at the same site.
\end{abstract}

Keywords: Cardiovascular implantable electronic devices infection, Rapid growing nontuberculous mycobacteria, $M$. Fortuitum, Case report

\section{Background}

In the last few decades, cardiac implantable electronic devices (CIEDs), which include permanent pacemakers (PMs), implantable cardioverter defibrillators (ICDs), and cardiac resynchronization therapy (CRT) devices have been widely utilized for the burgeoning aged

\footnotetext{
* Correspondence: jinbo7711@aliyun.com; chenqiying2006@163.com ${ }^{1}$ Department of Cardiology, Huashan Hospital of Fudan University, 12 Wulumuqi Zhong Road, Shanghai 200040, China

Full list of author information is available at the end of the article
}

population. As the survival benefits of CIED have been observed in clinical practice, their application is expected to increase. Despite the obvious benefits, the use of these implantable devices is also associated with serious complications. While improvements in implant technology have resulted in high success rates and lower occurrence of complications, an infection due to the device remains a major concern with the rate of secondary infection at about 1-2\% [1]. An infection of the CIED significantly increases the morbidity, mortality,

(c) The Author(s). 2019 Open Access This article is distributed under the terms of the Creative Commons Attribution 4.0 International License (http://creativecommons.org/licenses/by/4.0/), which permits unrestricted use, distribution, and reproduction in any medium, provided you give appropriate credit to the original author(s) and the source, provide a link to the Creative Commons license, and indicate if changes were made. The Creative Commons Public Domain Dedication waiver (http://creativecommons.org/publicdomain/zero/1.0/) applies to the data made available in this article, unless otherwise stated. 
and healthcare costs of the procedure by prolonging the hospitalization time and mandating an aggressive management of the patient. An implant-associated infection can occur early or may be delayed for several months after the procedure. The main pathogens implicated in CIED infections are Staphylococcus aureus and coagulase-negative staphylococci [2]. A CIED infection caused by non-tuberculous mycobacteria (NTM) is extremely rare. To our knowledge, an infection has been reported in only 37 post-implantation cases, 28 of which were caused by a rapidly growing mycobacteria (RGM). Here, we present a case of CRT-D pocket infection caused by Mycobacterium fortuitum, which is the first reported case of its kind in China. It is also the first instance in which, after a complete recovery from the infection, a new device was re-implanted in the patient at the same site.

\section{Case presentation}

A 68-year-old man had a history of chronic systolic heart failure and dilated cardiomyopathy, with a left ventricular ejection fraction of $32 \%$ and a left ventricular internal diastolic diameter of $81 \mathrm{~mm}$. His electrocardiograph had revealed a sinus rhythm with a QRS duration of $140 \mathrm{~ms}$ along with a left bundle branch block morphology. He underwent a cardiac resynchronization therapy-defibrillator (CRT-D) device implantation. However, 2 weeks after the procedure, he was re-admitted to our hospital with a 4-day history of pain and swelling at the CRT-D pocket site, associated with scant serous drainage. Prior to this admission, he had undergone a skin incision and drainage at another hospital, but the procedure had failed to relieve his symptoms. The patient had a history of hypertension, a myocardial bridge in the left anterior descending coronary artery and diabetes mellitus (on irregular therapy). He also had a history of pulmonary tuberculosis 40 years previously and had completed the curative treatment course successfully, at the time. His regular medications included metoprolol, perindopril, torsemide, and amiodarone.

During re-admission, the patient did not have complaints of fever, chills, or fatigue. The physical examination was unremarkable, except for a 2 -cm long, open incision on the upper left side of the chest, with mild localized edema over the CRT-D pocket. The skin around the incision was erythematous, and a small amount of scant serous discharge was noted on pressing the pocket site. Considering the likelihood of CRT-D infection, we collected the patient's blood samples to perform cultures for aerobic and anaerobic bacteria. The samples of the exudate were also tested, using microscopic examination and culture, not only for the usual causative bacteria but also for the rarer acid-fast bacilli. On initial microscopic examination, the exudate smear did not reveal any organisms. An echocardiogram showed no evidence of vegetation or thrombosis. Other laboratory test results, including a routine blood count and erythrocyte sedimentation rate, were within normal limits. The patient also tested negative for the human immunodeficiency virus (HIV) and the hepatitis B virus. He was started empirically on intravenous vancomycin and cefepime.

On the 3rd day of hospitalization, we performed a pocket reconstruction. The CRT-D was re-implanted below the pectoralis major muscle in the left pectoral region and connected with the pacing electrodes placed in the earlier pocket site through a subcutaneous tunnel. However, the incision site did not heal, and the localized edema worsened, with copious exudation from the drainage site. After the reoperation, the exudate was collected and cultured. Within 3 days, a smear test of the exudate revealed an acid-fast bacillus, and culture results showed a rapidly growing nontuberculous mycobacterium (RGM). As recommended by our infectious diseases department, the isolate was sent to the microbiology laboratory for a polymerase chain reaction test. An amplification of the bacterial $16 \mathrm{~S}$ ribosomal RNA gene, helped us identify the bacterial species as Mycobacterium fortuitum (M. fortuitum). The patient was therefore diagnosed with CRT-D infection due to M. fortuitum.

Once the causative organism was definitively identified, the patient's therapeutic antibiotic regimen was empirically changed to intravenous clarithromycin, moxifloxacin, and amikacin. At the same time, an incision and debridement of the first pocket site was performed, and the entire device along with the leads were extracted, percutaneously. With dedicated wound care, the swab culture tests eventually yielded negative results and the incision healed well. After 2 months of administration of combined intravenous treatment, the patient was discharged. He was further administered oral clarithromycin and moxifloxacin for 1 year. He was continued to follow up for next 2 years. During 3 years, we checked the pocket site every 3 months and evaluated his cardiac function by echocardiography, as well as recorded the QRS complex width by ECG. He remained asymptomatic of incision infection but we found that the patient's heart failure condition had gradually deteriorated (left ventricular ejection fraction decreased from 32 to 26\%) and life-threatening rapid ventricular arrhythmias occurred even under the optimal drug treatment. The patient was then re-implanted with another CRT-D device at nearly the same previous site. The symptoms of heart failure were significantly improved. ECG showed the QRS complex width was decreased from 140 $\mathrm{ms}$ to $112 \mathrm{~ms}$. Echocardiography showed the LVEF were increased to $45 \%$ after 6 months of the re-implantation. The patient has now remained free of infection over 4 years (Table 1 ). 
Table 1 Timeline

\begin{tabular}{ll}
\hline 2011.5 .30 & Implanted the cardiac resynchronization therapy-defibrillator device \\
\hline 2011.6 .11 & Onset of pain and swelling at his CRT-D pocket site \\
2011.6.15 & Empirically anti-infective treatment by intravenous Vancomycin and Cefepime. \\
2011.6.21 & Pocket reconstruction and CRT-D re-implanted below pectoralis major muscle at the left pectoral region. \\
2011.6 .23 & Incision was not healed and exudation was collected for culture \\
2011.6 .24 & Exudation smear was positive for acid-fast bacillus and culture results showed rapid growing nontuberculous mycobacteria(RGM) \\
2011.6 .25 & PCR amplification of the bacterial 16S ribosomal RNA gene, it was identified as Mycobacterium fortuitum. \\
2011.6 .25 & Antibacterial treatment: Clarithromycin and Moxifloxacin and Amikacin for 2 months. \\
2011.8 .25 & Therapy with oral Clarithromycin and Moxifloxacin for one year. \\
2012.8 & Stop antibacterial treatment \\
2013.8 & Follow- up after one year \\
2014.8 & Follow-up two years and received a new CRT-D device implantation. \\
2018.8 & Follow-up four-years after new device implanted. No symptoms of any infection. \\
\hline
\end{tabular}

\section{Discussion and conclusions}

With growing evidence that a CIED implant is of benefit to patients with chronic cardiac disease, the utilization of these devices has increased over the last few years. The incidence of CIED infection is therefore correspondingly on the rise. The reported rates of infection secondary to CIED implantation, differ across various studies, ranging from 0.13 to $19.9 \%$. The most recent studies report a rate of infection between 1 and $2 \%$ $[3,4]$.

The risk factors for CIED infections include prior immunodeficient states, i.e. patients suffering from HIV infection, diabetes mellitus, and chronic renal insufficiency are at a greater risk. In addition, many studies have found a higher rate of infection associated with ICDs or CRT devices, nearly 2-5 times higher than that associated with PM $[5,6]$. This may be due to the larger sizes of the ICD and CRT devices and the longer operative duration required for implanting them. The use of anticoagulants has been associated with a higher risk of pocket hematoma, which also exacerbates the risk of a generator pocket infection.

Gram-positive bacteria are the predominant causative pathogens of CIED infections. Coagulase-negative staphylococci and Staphylococcus aureus account for 70-80\% of all infections following CIED implantations [7]. However, RGM infections in implanted cardiac devices are still very rare. We searched the PubMed database for any older studies (no specified start time), case reports, or reviews related to CIED infections, using several search strings that combined the names of the various NTM with the different implantable cardiac devices. To be more specific, we used the following free text terms: (rapid growing nontuberculous mycobacteria OR nontuberculous mycobacteria OR Mycobacterium fortuitum OR Mycobacterium chelonae OR Mycobacterium abscessus OR Mycobacterium smegmatis group OR Mycobacterium mucogenicum) AND (cardiovascular implantable electronic devices OR CIED OR pacemaker OR PM OR cardiac resynchronization therapy OR CRT OR cardiac resynchronization therapy-defibrillator OR CRT-D OR implantable cardioverter defibrillator OR ICD). A review published by Phadke et al. summarized 23 cases with CIED infection caused by RGM up to March 31, 2015 [8]. Including the cases in their study, we found records for a total of 27 older cases that were identified as CIED infections due to RGM [8-30]. This makes our patient only the 28th recorded case of CIED infection, caused by an RGM species.

RGM comprise approximately half of the currently known mycobacterial species and are divided into five major groups: Mycobacterium fortuitum, $M$. chelonae/M. abscessus complex, M. smegmatis, $M$. mucogenicum, and the pigmented RGM [31]. The RGM species are universal organisms that exist in soil, food, natural and tap water, as well as in various plants and animals [32, 33]. They can grow in municipal water systems as well as distilled water and are resistant to sterilizers, antiseptics, and other standard disinfectants [33, 34]. The most commonly encountered RGM species in clinical practice are $M$. fortuitum and $M$. abscessus/M. chelonae. Of the recorded 28 CIED infections caused by RGM (Table 2), 17 (61\%) were reportedly caused by M. fortuitum. We found 4 reported cases each, of CIED infections caused by the Mycobacterium abscessus/chelonae complex and the Mycobacterium smegmatis group. Only 2 patients were found to be infected by the Mycobacterium mageritense group and the pigmented RGM were identified only in 1 case. While $16(60 \%)$ patients had infections associated with permanent PMs and 9 patients presented 
Table 2 Clinical and demographic information for published cases of cardiac device infections due to rapidly growing mycobacteria

\begin{tabular}{|c|c|c|c|c|c|c|c|c|c|}
\hline Reference & $\begin{array}{l}\text { Age } \\
\text { (years) } \\
\text { /sex }\end{array}$ & Onset $^{\mathrm{a}}$ & Type & Bacteremia $^{b}$ & $\mathrm{IE}^{\mathrm{C}}$ & Organism & $\begin{array}{l}\text { Device } \\
\text { Removal }\end{array}$ & Antibiotics Treatment/Duration & Outcon \\
\hline \multicolumn{10}{|c|}{ Mycobacterium fortuitum group } \\
\hline Verghese, 1998 & $74 / \mathrm{M}$ & $13 d$ & PPM & NR & $N R$ & $\begin{array}{l}\text { Mycobacterium fortuitum / } \\
\text { Mycobacterium chelonae }\end{array}$ & Yes & $\begin{array}{l}\text { Fluoroquinolone + Aminoglycoside } \\
/ 1 \mathrm{mo}\end{array}$ & Cured \\
\hline Sharma, 2005 & $62 / F$ & $6 \mathrm{mo}$ & PPM & Yes & Yes & Mycobacterium fortuitum & Yes & $\begin{array}{l}\text { Clarithromycin + Ciprofloxacin/4wk, } \\
\text { Doxycycline+ Ciprofloxacin /24wk }\end{array}$ & Cured \\
\hline Short,2005 & $74 / \mathrm{M}$ & 6 wk & $I C D$ & Yes & $N R$ & Mycobacterium fortuitum & Yes & Clarithromycin + Ciprofloxacin /6wk & Cured \\
\hline $\begin{array}{l}\text { Hemmersbach- } \\
\text { Miller,2005 }\end{array}$ & $72 / \mathrm{M}$ & $2 w k$ & PPM & No & No & Mycobacterium fortuitum & Yes & $\begin{array}{l}\text { Ciprofloxacin + Aminoglycoside } \\
\text { /2wk, Ciprofloxacin / } 6 \mathrm{mo}\end{array}$ & Cured \\
\hline $\begin{array}{l}\text { Hemmersbach- } \\
\text { Miller,2005 }\end{array}$ & $61 / \mathrm{M}$ & $17 \mathrm{mo}$ & ICD & No & No & Mycobacterium fortuitum & Yes & Levofloxacin $/ \geq 1 \mathrm{yr}$ & Cured \\
\hline Pastor, 2006 & $80 / \mathrm{M}$ & $18 d$ & PPM & Yes & No & Mycobacterium fortuitum & No & Ciprofloxacin + Clarithromycin/6 wk & Cured \\
\hline Giannella, 2007 & $84 / F$ & $2 \mathrm{mo}$ & PPM & No & No & Mycobacterium fortuitum & Yes & Levofloxacin/3 mo & Cured \\
\hline Siu, 2007 & $78 / F$ & $6 \mathrm{mo}$ & PPM & Yes & No & Mycobacterium fortuitum & Yes & Levofloxacin + Clarithromycin/6 mo & Cured \\
\hline Tam, 2007 & $78 / F$ & $4 \mathrm{mo}$ & PPM & Yes & NR & Mycobacterium fortuitum & Yes & Levofloxacin + Clarithromycin/6 mo & Cured \\
\hline $\begin{array}{l}\text { Al Soub H, } \\
2009\end{array}$ & $15 / F$ & 7 wk & PPM & Yes & No & Mycobacterium fortuitum & Yes & Ciprofloxacin + Clarithromycin/6 mo & Cured \\
\hline Van Duin,2010 & 78/M & NR & PPM & Yes & NR & Mycobacterium fortuitum & Yes & Ciprofloxacin + Clarithromycin/26wk & Cured \\
\hline Sharma,2012 & $43 / \mathrm{M}$ & $4 \mathrm{yr}$ & ICD & Yes & Yes & Mycobacterium fortuitum & Yes & $\begin{array}{l}\text { Ciprofloxacin + Clarithromycin+ } \\
\text { Aminoglycoside }\end{array}$ & Died \\
\hline Amraoui,2012 & $75 / \mathrm{M}$ & $1 \mathrm{yr}$ & PPM & Yes & No & Mycobacterium peregrinum & Yes & Ciprofloxacin + Clarithromycin/mo & Cured \\
\hline Yuhning,2012 & $56 / \mathrm{M}$ & $4 \mathrm{mo}$ & ICD & Yes & No & Mycobacterium fortuitum & No & $\begin{array}{l}\text { Cephalexin, Clarithromycin+ } \\
\text { Moxifloxacin/ } 2 \text { wk }\end{array}$ & Died \\
\hline Varun,2016 & $60 / \mathrm{M}$ & $6 w k$ & ICD & Yes & No & Mycobacterium fortuitum & Yes & $\begin{array}{l}\text { Ciprofloxacin + Clarithromycin+ } \\
\text { Cefoxitin }\end{array}$ & Died \\
\hline $\begin{array}{l}\text { Menfil } \\
\text { Orellana- } \\
\text { Barriors,2017 }\end{array}$ & $59 / F$ & $3 w k$ & ICD & No & No & Mycobacterium fortuitum & Yes & $\begin{array}{l}\text { Levofloxacin + Clarithromycin/23 } \\
\text { wk }\end{array}$ & Cured \\
\hline $2018^{d}$ & $68 / F$ & $10 d$ & CRT & No & No & Mycobacterium fortuitum & Yes & $\begin{array}{l}\text { Clarithromycin + Moxifloxacin/12 } \\
\text { mo }\end{array}$ & Cured \\
\hline \multicolumn{10}{|c|}{ Mycobacterium chelonaelabscessus complex } \\
\hline Cutay, 1998 & $68 / \mathrm{M}$ & $19 \mathrm{yr}$ & PPM & NR & NR & Mycobacterium abscessus & Yes & $\begin{array}{l}\text { Clarithromycin + Cefoxitin + } \\
\text { Amikacin/5 wk }\end{array}$ & Died \\
\hline Kessler, 2004 & $53 / F$ & $2 w k$ & $I C D$ & NR & NR & Mycobacterium abscessus & Yes & Clarithromycin/6 mo & Cured \\
\hline $\begin{array}{l}\text { Simmon } \\
\text { KE,2007 }\end{array}$ & $43 / F$ & $11 \mathrm{mo}$ & PPM & NR & NR & Mycobacterium massiliense & Yes & Clarithromycin/6 mo & Cured \\
\hline Hooda,2014 & $63 / \mathrm{M}$ & NR & PPM & No & Yes & Mycobacterium chelonae & Yes & $\begin{array}{l}\text { Clarithromycin + Levofloxacin + } \\
\text { Aminoglycoside / } 2 \text { mo }\end{array}$ & Cured \\
\hline \multicolumn{10}{|c|}{ Mycobacterium smegmatis group } \\
\hline Toda H,2006 & $86 / \mathrm{M}$ & $16 d$ & PPM & Yes & NR & Mycobacterium goodii & Yes & Minocycline + Aminoglycoside /2wk & Cured \\
\hline $\begin{array}{l}\text { Chrissoheris } \\
\text { MP,2008 }\end{array}$ & $85 / \mathrm{M}$ & $<7 d$ & ICD & No & No & Mycobacterium goodii & Yes & $\begin{array}{l}\text { Trimethoprim/Sulfamethoxazole } \\
\text { /8wk }\end{array}$ & Cured \\
\hline $\begin{array}{l}\text { Marchandin H, } \\
2009\end{array}$ & $23 / \mathrm{M}$ & $8 d$ & PPM & No & No & Mycobacterium goodii & No & $\begin{array}{l}\text { Doxycycline +Fluoroquinolone } \\
\text { /6mo }\end{array}$ & Cured \\
\hline David,2016 & $74 / F$ & $1 \mathrm{mo}$ & PPM & No & No & Mycobacterium goodii & Yes & Ciprofloxacin + Doxycycline/6mo & Cured \\
\hline \multicolumn{10}{|c|}{ Mycobacterium mageritense group } \\
\hline Tam, 2007 & $77 / F$ & $3 w k$ & PPM & NR & NR & $\begin{array}{l}\text { Mycobacterium } \\
\text { mageritense }\end{array}$ & No & Levofloxacin/6 mo & Cured \\
\hline Masato & $59 / F$ & $14 d$ & ICD & Yes & No & Mycobacterium & Yes & Ciprofloxacin + Clarithromycin/ 1 yr & Cured \\
\hline
\end{tabular}


Table 2 Clinical and demographic information for published cases of cardiac device infections due to rapidly growing mycobacteria (Continued)

\begin{tabular}{|c|c|c|c|c|c|c|c|c|c|}
\hline Reference & $\begin{array}{l}\text { Age } \\
\text { (years) } \\
\text { /sex }\end{array}$ & Onset $^{a}$ & Type & Bacteremia $^{b}$ & $\mathrm{IE}^{\mathrm{C}}$ & Organism & $\begin{array}{l}\text { Device } \\
\text { Removal }\end{array}$ & Antibiotics Treatment/Duration & Outcome \\
\hline $\begin{array}{l}\text { Fukunaga, } \\
2016\end{array}$ & & & & & & mageritense & & & \\
\hline \multicolumn{10}{|c|}{ The pigmented rapid growing species } \\
\hline $\begin{array}{l}\text { Karnam S, } \\
2011\end{array}$ & $73 / F$ & $1 \mathrm{mo}$ & $I C D$ & No & $N R$ & Mycobacterium phlei & Yes & $\begin{array}{l}\text { Trimethoprim/Sulfamethoxazole } \\
\text { +Doxycycline } / 12 \text { mo }\end{array}$ & Cured \\
\hline \multicolumn{10}{|c|}{$\begin{array}{l}\text { ICD implantable cardioverter-defibrillator, PPM permanent pace } \\
d \text { day } \\
{ }^{a} \text { Time since most recent device manipulation } \\
{ }^{b} \text { Defined as positive blood culture, acid fast stain } \\
{ }^{C} \text { Transthoracic or transesophageal echocardiographic findings } \\
{ }^{d} \text { The patient described in this article }\end{array}$} \\
\hline
\end{tabular}

with ICD infection, we found no previous reports of CIED following a CRT-D implantation procedure, which makes our case report the first of its kind with respect to the type of device involved. Of the 28 patients, 21 patients $(75 \%)$ developed an infection in $<6$ months after the device implantation, of which, 12 patients were affected within 4 weeks. Therefore, we can surmise that the patients presenting with an early-onset infection are likely to have contracted it primarily during the implantation procedure and not as a secondary infection through the bloodstream. Only 4 of the 28 cases developed clinical manifestations of an infection $>1$ year after device implantation. To our knowledge, M. fortuitum is not considered a normal skin commensal. These infections are considered to have been postoperatively contracted from an environmental source. We observed that $13(46 \%)$ of the 28 reported patients with an RGM infection had other associated infections caused by mycobacteria. While 3 of these 13 patients were found to fulfil the clinical criteria for infective endocarditis through echocardiographic findings, in 1 patient, the causative mycobacterium was isolated on culture postoperatively, thus fulfilling the pathologic criteria of diagnosis.

The CIED infections are generally categorized as superficial or deep infections. The superficial infections like a generator pocket infection are commoner than the deep infections affecting the cardiac leads or valves. The most common manifestations of a generator pocket infection are fever, pain at the generator site, and wound discharge. Therefore, when an operated patient is observed to have slow wound healing or has a history of the implant site being re-opened and re-manipulated for any reason, an RGM infection should be strongly suspected (especially in an immunocompromised host). However, while a patient with an RGM may present with localized redness, swelling, and with spontaneous drainage, the typical systemic symptoms of fever, chills and fatigue are absent. The wound exudate is usually thin and watery but may sometimes be thick and purulent [33]. An echocardiography along with cultures of the patient's blood, device pocket tissue, and leads are essential for the diagnostic evaluation. The tissue cultures of samples obtained during the surgery are more sensitive than swab cultures [35].

While the management of RGM infections must be tailored individually, an urgent device removal followed by antimicrobial therapy forms the mainstay of treatment in all cases. An American Heart Association statement recommended a complete removal of all hardware (Class I evidence) from patients, even in the absence of signs of systemic infection. An incomplete removal of CIED has resulted in higher infection relapse rates. These organisms can form biofilms, which make them difficult to eradicate with antimicrobial drug therapy alone. In our case, the device was urgently extracted from the patient and 3 years later, once he was disease-free, he was re-implanted with another device, which suggests the possibility of re-implantation after cure in other such patients.

After removal of the device, antibiotic treatment is essential. An antimicrobial drug susceptibility test is important for the selection of the appropriate antibiotic therapy. A recommended diagnostic and therapeutic flow chart is shown in Fig. 1. M. fortuitum is usually found to be susceptible to amikacin, cefoxitin, sulfonamides, ciprofloxacin, imipenem and moxifloxacin, with about half of the isolates susceptible to doxycycline [36]. Approximately $80 \%$ of $M$. fortuitum isolates can be inhibited by clarithromycin. Among newer antimicrobials, linezolid has been shown to have in vitro activity against the $M$. fortuitum group [37]. Unfortunately, most of the effective antimicrobial drugs for RGM have potentially adverse proarrhythmic effects. In our patient, we regretted the fallacy of prescribing antimicrobials empirically, without an initial drug susceptibility test. The treatment duration is dependent on the completeness of device removal, the greater the number of components 


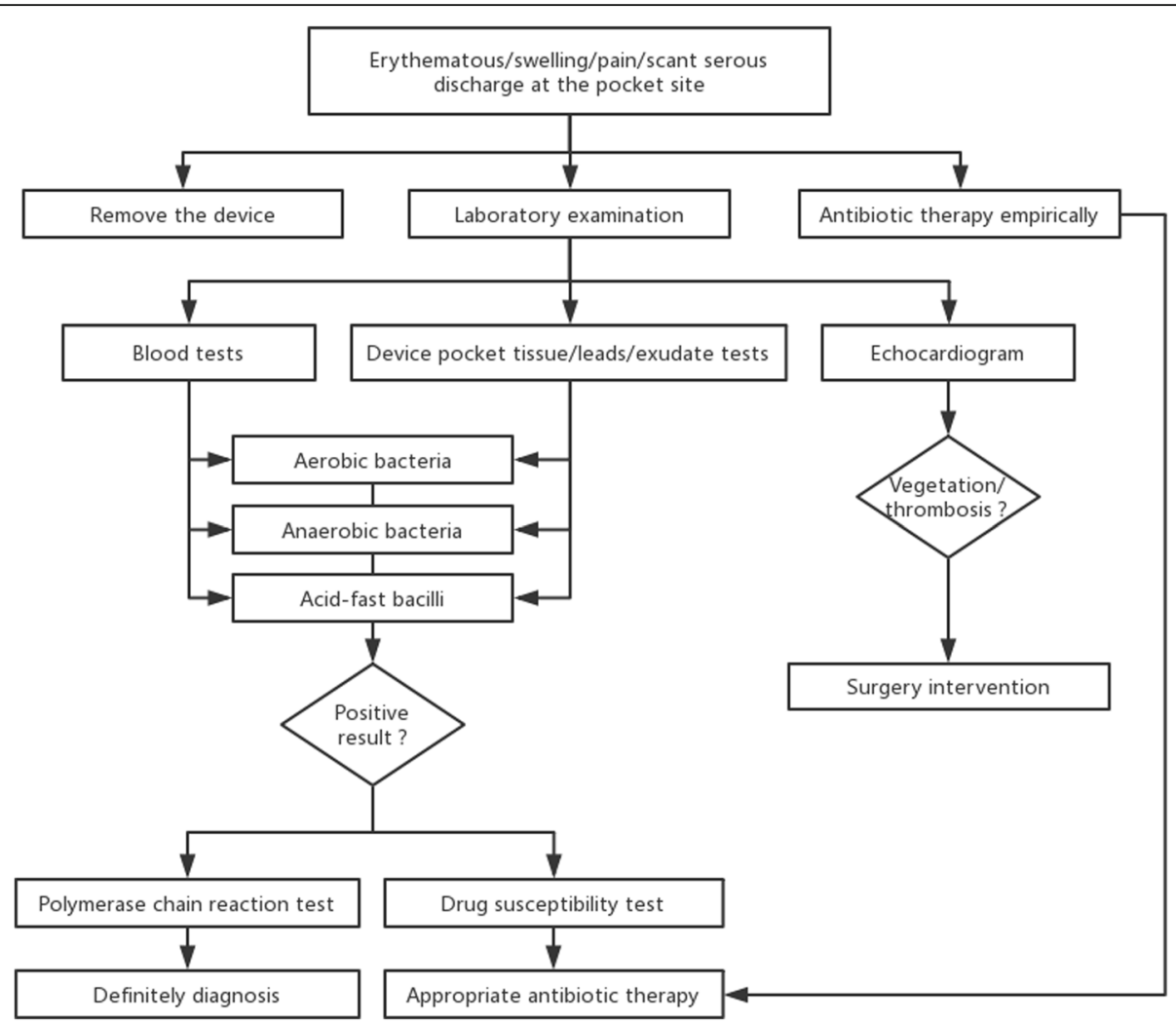

Fig. 1 A recommended diagnostic and therapeutic of CIED infections flow chart

of a device left in situ, the longer the duration of treatment. A longer duration of antibacterial therapy is necessary due to the propensity of the organisms towards biofilm formation. In 16 of the 28 recorded cases, the antibiotic treatment duration was $\geq 6$ months. The optimal timing of device replacement after removal is not defined, as it may vary individually, depending on the extent of infection in each patient. It is recommended that the device should be replaced on the contralateral side from the older infected site [35]. In our patient, we implanted a new CRT-D, 3 years after the removal of the older infected device. As a generator placed on the right side could decrease the effect of defibrillation, the new device was implanted on the same side (left side) as before. Over 3 years of follow-up, the patient has shown no recurrence of an RGM infection.

Preventive measures are extremely important to minimize the risk of infection. A microbial contamination can occur during implantation, post-implantation or can occur secondary to an erosion of the device through skin. Several observational studies have demonstrated that almost half of the CIED infections can be prevented by prophylactic antibiotic therapy administered in the perioperative period [38]. The risk of infection is proportional to the duration of the implantation procedure. Therefore, we can reduce risk of CIED infections by strict aseptic manipulation, perioperative antibiotic prophylaxis, and by limiting the operative duration. Furthermore, temporary pacing should be avoided, if possible, because temporary transvenous pacing is associated with an increased risk of infection [39]. The utilization of newer devices such as subcutaneous defibrillators, leadless pacemakers and bio-absorbable antibacterial envelopes may also contribute to decreasing the incidence of infection in patients with CIED [40-43].

The infections occurring after implantation of cardiac devices and caused by nontuberculous mycobacteria are rare. However, with an increased utilization of cardiac implant devices in patients, the occurrence of consequent infections is also expected to increase. Our patient presented with typical manifestations of a post-implantation CIED infection caused by RGMs, including early onset with localized implant site redness, swelling, spontaneous drainage, and without any systemic symptoms. After identifying $M$. fortuitum, as the causative organism, the device was completely removed at once, and the appropriate antibiotic therapy was administered. The treatment had a successful outcome as our patient was completely cured. The limitation of our case was that we prescribed antimicrobials empirically, without an initial drug susceptibility test. Furthermore, 
we implanted another device in the same patient after 3 years, which is an encouraging indication that re-implantation after the resolution of infection in other such patients may be possible. However, further investigation is required to determine the suitable time interval between the successful completion of curative treatment and re-implantation.

\section{Abbreviations}

CIED: Cardiovascular implantable electronic devices; CRT-D: Cardiac resynchronization therapy-defibrillator; ICD: Implantable cardioverter defibrillator; NTM: Non-tuberculous mycobacteria; PM: Permanent pacemaker; RGM: Rapid growing nontuberculous mycobacteria

\section{Acknowledgements}

We gratefully acknowledge Dr. Yong Li for his editorial suggestions.

\section{Funding}

This study was supported in part by grants from the National Natural

Science Foundation in China (No.81470496 and No.81573710).

\section{Availability of data and materials}

All the data supporting our findings is contained within the manuscript.

\section{Authors' contributions}

JZ and QY are equal to contribute to this manuscript. JZ participated in the entire treatment process. QY drafted the manuscript. BJ and QC conceived and designed the study. JP and HS reviewed and edited the manuscript. All authors have read and approved the final manuscript.

\section{Ethics approval and consent to participate}

We identified this patient during routine clinical practice and consented to give venous blood samples after elaborate information. Involvement of the ethical committee of the Huashan Hospital of Fudan University was considered unnecessary, since the project was not based on a study protocol.

\section{Consent for publication}

Written informed consent was obtained from the patient for publication of this case report and any accompanying images.

\section{Competing interests}

The authors declare that they have no competing interests.

\section{Publisher's Note}

Springer Nature remains neutral with regard to jurisdictional claims in published maps and institutional affiliations.

\section{Author details}

'Department of Cardiology, Huashan Hospital of Fudan University, 12 Wulumuqi Zhong Road, Shanghai 200040, China. ${ }^{2}$ Department of infectious Diseases, Huashan Hospital of Fudan University, 12 Wulumuqi Zhong Road, Shanghai 200040, China.

Received: 9 November 2018 Accepted: 20 February 2019 Published online: 05 March 2019

\section{References}

1. Leung S, Prevention DS. Diagnosis, and treatment of cardiac implantable electronic device infections. Curr Cardiol Rep. 2016;18(6):58

2. Chua J, Wilkoff B, Lee I, Juratli N, Longworth D, Gordon S. Diagnosis and management of infections involving implantable electrophysiologic cardiac devices. Ann Intern Med. 2000;133(8):604-8.

3. Polyzos KA, Konstantelias AA, Falagas ME. Risk factors for cardiac implantable electronic device infection: a systematic review and metaanalysis. Europace. 2015:17(5):767-77.

4. Rahman R, Saba S, Bazaz R, Gupta V, Pokrywka M, Shutt K, et al. Infection and readmission rate of cardiac implantable electronic device insertions: an observational single center study. Am J Infect Control. 2016;44(3):278-82.
5. Daniel Z, Uslan MRS, Friedman PA, Hayes DL, Wilson WR, Steckelberg JM, Baddour LM. Frequency of permanent pacemaker or implantable cardioverter-defibrillator infection in patients with gram-negative bacteremia. Clin Infect Dis. 2006:43:731-6.

6. Johansen JB, Jorgensen OD, Moller M, Arnsbo P, Mortensen PT, Nielsen JC. Infection after pacemaker implantation: infection rates and risk factors associated with infection in a population-based cohort study of 46299 consecutive patients. Eur Heart J. 2011;32(8):991-8.

7. Arnold C, Chu V. Cardiovascular Implantable Electronic Device Infections. Infect Dis Clin N Am. 2018;32(4):811-25.

8. Phadke VK, DSH NDG. Patient report and review of rapidly growing mycobacterial infection after cardiac device implantation. Emer Infect Dis. 2016;22(3):389-95.

9. Cutay A, Horowitz H, Pooley R, Van Horn K, Wormser G. Infection of epicardial pacemaker wires due to Mycobacterium abscessus. Clin Infect Dis. 1998;26(2):520-1.

10. Verghese S, Mullaseri A, Padmaja P, Subhadra A, Cherian K. Pacemaker implant site infection caused by atypical mycobacteria. Indian Heart J. 1998; 50(2):201-2

11. Kessler A, Kourtis A. Mycobacterium abscessus as a cause of pacemaker infection. Med Sci Monit. 2004;10(10):CS60-2.

12. Hemmersbach-Miller M, Cardenes-Santana MA, Conde-Martel A, BolañosGuerra JA, Campos-Herrero Ml. Cardiac device infections due to Mycobacterium fortuitum. Can J Infect Dis Med Microbiol. 2005;16(3):183-5.

13. Sharma S, Tleyjeh I, Espinosa R, Costello B, Baddour L. Pacemaker infection due to Mycobacterium fortuitum. Scand J Infect Dis. 2005;37(1):66-7.

14. Short WR, Emery C, Bhandary M, O'Donnell JA. Misidentification of Mycobacterium peregrinum, the causal organism of a case of bacteremia and automatic implantable cardioverter defibrillator-associated infection, due to its unusual acid-fast staining characteristics. J Clin Microbiol. 2005; 43(4):2015-7.

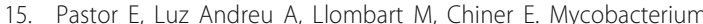
fortuitum: a rare cause of pacemaker infection. Enferm Infecc Microbiol Clin. 2006:24(2):136-7.

16. Toda H, Sato K, limori M, Yamazumi T, Furuta I, Satoh A, et al. A case of Mycobacterium goodii infection wifh isolation from blood and a pacemaker lead. J Jpn Assoc Infect Dis. 2006;80(3):262-6.

17. Giannella M, Valerio M, Franco JA, Marin M, Bouza E, Munoz P. Pacemaker infection due to Mycobacterium fortuitum: the role of universal 16S rRNA gene PCR and sequencing. Diagn Microbiol Infect Dis. 2007:57(3):337-9.

18. Simmon KE, Pounder Jl, Greene JN, Walsh F, Anderson CM, Cohen S, et al. Identification of an emerging pathogen, Mycobacterium massiliense, by rpoB sequencing of clinical isolates collected in the United States. J Clin Microbiol. 2007;45(6):1978-80.

19. Siu CW, Cheng LC, Woo PC, Lau CP, Tse HF. A patient with relapsing pacemaker infection due to "gram-positive bacilli". Int J Cardiol. 2007; 114(2):E40-1.

20. Tam W, Yew W, Yam W, Yuen K, Wong P, Tse T. Pacemaker infections due to rapidly growing mycobacteria: further experience. Int J Tuberc Lung Dis. 2007;11(1):118.

21. Chrissoheris M, Kadakia H, Marieb M, Libertin C. Pacemaker pocket infection due to Mycobacterium goodii: case report and review of the literature. Conn Med. 2008:72(2):75-7.

22. Al Soub H, Al Maslamani M, Al Khuwaiter J, El Deeb Y, Abu Khattab M. Myocardial abscess and bacteremia complicating Mycobacterium fortuitum pacemaker infection: case report and review of the literature. Pediatr Infect Dis J. 2009;28(11):1032-4.

23. He'le'ne Marchandin, Battistella, P, Brigitte Calvet, Hé le` ne Darbas J-MF, He' le' ne Jean-Pierre,Sylvie Parer,Estelle Jumas-Bilak, Philippe Van de Perre and Sylvain Godreuil. Pacemaker surgical site infection caused by Mycobacterium goodii. J Med Microbiol 2009;58:517-520.

24. van Duin D, Goldfarb J, Schmitt SK, Tomford JW, Tuohy MJ, Hall GS. Nontuberculous mycobacterial blood stream and cardiac infections in patients without HIV infection. Diagn Microbiol Infect Dis. 2010;67(3):286-90.

25. Karnam S, Alla V, Kwon J, Harbert T, Sharma A, Airey K, et al. Mycobacterium phlei, a previously unreported cause of pacemaker infection: thinking outside the box in cardiac device infections. Cardiol J. 2011;18(6):687-90.

26. Amraoui S, Texier-Maugein J, Bordachar P. PET scan in suspected but unproven pacemaker endocarditis. Arch Cardiovasc Dis. 2012;105(2):125-6.

27. Sharma H, Keshavan A, Little MA, Cross J, Lipman MC, Talukdar S, et al. Fortuitous vasculitis. Ren Fail. 2012;34(3):378-82. 
28. Hooda A, Pati PK, John B, George PV, Michael JS. Disseminated Mycobacterium chelonae infection causing pacemaker lead endocarditis in an immunocompetent host. BMJ Case Rep. 2014;2014. PMID:25535221. https://doi.org/10.1136/bcr-2014-206042.

29. Fukunaga M, Goya M, Ogawa M, Fukuda K, Taniguchi H, Ando K, et al. Implantable cardioverter defibrillator infection due to Mycobacterium mageritense. J Infect Chemother. 2016;22(3):180-3.

30. Orellana-Barrios M, Sotello Aviles DA, Oyenuga O, Nugent K. Implantable cardiac defibrillator infections: the emerging importance of Mycobacterium fortuitum. BMJ Case Rep. 2017;2017. PMID:28928258. https://doi.org/10. 1136/bcr-2017-221934

31. Brown-Elliott BA, Philley JV. Rapidly growing mycobacteria. Microbiol Spectr. 2017:5(1). PMID:28084211. https://doi.org/10.1128/microbiolspec.TNMI70027-2016.

32. III JOF. The changing pattern of nontuberculous mycobacterial disease. Can J Infect Dis. 2003;14(5):281-6.

33. Brown-Elliott BA, Wallace RJ. Clinical and taxonomic status of pathogenic nonpigmented or late-pigmenting rapidly growing mycobacteria. Clin Microbiol Rev. 2002;15(4):716-46.

34. Gubler JGH, Salfinger M. Graevenitz Av. Pseudoepidemic of nontuberculous mycobacteria due to a contaminated bronchoscope cleaning machine. Chest. 1992:101(5):1245-9.

35. Baddour LM, Epstein AE, Erickson CC, Knight BP, Levison ME, Lockhart PB, et al. Update on cardiovascular implantable electronic device infections and their management: a scientific statement from the American Heart Association. Circulation. 2010;121(3):458-77.

36. Wallace RJ, Brown-Elliott BA, Crist CJ, Mann L, Wilson RW. Comparison of the in vitro activity of the Glycylcycline Tigecycline (formerly GAR936) with those of tetracycline, minocycline, and doxycycline against isolates of nontuberculous mycobacteria. Antimicrob Agents Chemother. 2002:46(10):3164-7.

37. Wallace RJ Jr, Brown-Elliott BA, Ward SC, Crist CJ, Mann LB, Wilson RW. Activities of linezolid against rapidly growing mycobacteria. Antimicrob Agents Chemother. 2001;45(3):764-7.

38. Sohail MR, Uslan DZ, Khan AH, Friedman PA, Hayes DL, Wilson WR, et al. Risk factor analysis of permanent pacemaker infection. Clin Infect Dis. 2007; 45(2):166-73.

39. Klug D, Balde M, Pavin D, Hidden-Lucet F, Clementy J, Sadoul N, et al. Risk factors related to infections of implanted pacemakers and cardioverter-defibrillators: results of a large prospective study. Circulation. 2007;116(12):1349-55.

40. Weiss R, Knight B, Gold M, Leon A, Herre J, Hood M, et al. Safety and efficacy of a totally subcutaneous implantable-cardioverter defibrillator. Circulation. 2013:128(9):944-53.

41. Mittal S, Shaw R, Michel K, Palekar R, Arshad A, Musat D, et al. Cardiac implantable electronic device infections: incidence, risk factors, and the effect of the AigisRx antibacterial envelope. Heart Rhythm. 2014;11(4):595-601.

42. Reddy VY, Exner DV, Cantillon DJ, Doshi R, Bunch TJ, Tomassoni GF, et al. Percutaneous implantation of an entirely Intracardiac leadless pacemaker. N Engl J Med. 2015;373(12):1125-35.

43. Reynolds D, Duray GZ, Omar R, Soejima K, Neuzil P, Zhang S, et al. A leadless Intracardiac Transcatheter pacing system. N Engl J Med. 2016; 374(6):533-41

Ready to submit your research? Choose BMC and benefit from:

- fast, convenient online submission

- thorough peer review by experienced researchers in your field

- rapid publication on acceptance

- support for research data, including large and complex data types

- gold Open Access which fosters wider collaboration and increased citations

- maximum visibility for your research: over $100 \mathrm{M}$ website views per year

At BMC, research is always in progress.

Learn more biomedcentral.com/submissions 